\title{
Relative Frequencies and Patterns of Malignant Lymphoma in a Reference Centre in Khartoum, Sudan: A Descriptive Study Based on the WHO Classification of Lymphoid Neoplasms
}

\author{
Ezeldine K Abdalhabib
}

Department of Clinical Laboratory Sciences- College of Applied Medical Sciences-Qurayyat-Jouf University- Saudi Arabia.

\begin{abstract}
Background: The effective management and choice of appropriate treatment of lymphoma subtypes depend on an accurate diagnosis and differentiation, which require comprehensive haematology and pathology work. Methods: A total of 134 cases of malignant lymphoma, newly diagnosed between January 2017 to January 2020, were selected. For each patient's samples, complete blood count, immunohistochemistry, and morphological evaluation were done. Results: Clinical data showed that 81 patients $(60.4 \%)$ were males and $53(39.6 \%)$ females. The age range was 4 to 80 years. NHL lymphoma comprised $87.3 \%$ of cases, while HL comprised $12.7 \%$ of cases. Diffuse large B cell lymphoma was the most prevalent NHL subtype, representing $39.3 \%$ of cases. Among HL subtypes, mixed cellularity was present in $41.2 \%$ of cases. B cell lymphoma constituted $93.2 \%$ of cases. All HL patients and $74.4 \%$ of NHL patients had anaemia. Conclusion: This is the first statistical report of malignant lymphoma patterns in Sudanese patients. These data suggest that malignant lymphoma in Sudanese patients is more frequent in males than females; its incidence increases with age. Further, B cell lymphoma is more common than T cell lymphoma. Diffuse large B cell lymphoma was the most frequent NHL subtype.
\end{abstract}

Keywords: Malignant Lymphoma- Lymphoid Neoplasms- Sudan- frequencies- subtypes

Asian Pac J Cancer Care, 5 (2), 107-112

Submission Date: 04/24/2020Ａcceptance Date: 06/15/2020

\section{Introduction}

Lymphomas comprise a heterogeneous group of clinically distinct neoplasms with varied aetiologies, outcomes, and treatment strategies [1-2]. The main types of lymphoma are non-Hodgkin lymphomas (NHL) and Hodgkin lymphomas (HL) ad defined by the lymphoid cells from which the neoplasm originates, which can be either B-cell, T-cell or NK-cell neoplasms. The World Health Organization (WHO) classifies lymphomas in more than 90 subtypes, including provisional types [3]. According to reports of the International Agency for Research on Cancer (IARC), the incidence rate of lymphoma is $3.5 \%$ of all cancers, with 589,580 new patients worldwide in 2018 and 274,891 deaths from the disease [4].

Although several reports exist regarding the distribution of malignant lymphomas in different parts of the world, no studies have been previously

reported on the pattern of malignant lymphoma in Sudan. In Sudan, lymphoma represents the fourth most prevalent type of cancer in adults and the second in children's neoplasms [5]. The effective management and choice of appropriate treatment of lymphoma subtypes depend on an accurate diagnosis and differentiation, which require comprehensive haematology and pathology work. Immunohistochemistry is an essential diagnostic tool for distinguishing different lymphoma subtypes, besides histopathological evaluation of patient's samples. The presence of irregular margins in aggregated atypical lymphocytes is the main feature of malignant lymphoid cells [6]. However, indistinct cases are seen sometimes when biopsy samples are stained with routine stain only, i.e. haematoxylin and eosin (H\&E), which has a significant impact on the treatment plan. Morphological evaluation, together with immunophenotyping and genetic studies,

Corresponding Author:

Dr. Ezeldine K Abdalhabib

Department of Clinical Laboratory Sciences- College of Applied Medical Sciences-Qurayyat-Jouf University- Saudi Arabia.

Email: ezeldine2008@yahoo.com 
must be employed to achieve an accurate diagnosis for malignant lymphoma [7]. Immunohistochemistry is widely used for diagnosis and differentiation of malignant lymphoma [8]. The most commonly used biomarkers are CD3 and CD20 for T cell and B cell lymphoma, respectively [9]. The expression of biomarkers on lymphoid cells and subclasses of lymphoma are a dependent factor in the therapeutic intervention [10]. This study aims to investigate the relative frequency and pattern of different types of malignant lymphomas in Sudanese patients, according to the WHO classification of lymphoid neoplasms.

\section{Materials and Methods}

The current cross-sectional descriptive study was conducted at Radioisotope Centre of Khartoum (RICK), which is the reference oncology centre in Sudan. The study subjects included 134 newly diagnosed patients with different subtypes of HL or NHL of three years duration, diagnosed between January 2017 and January 2020. Ethical approval was obtained from the institutional ethical board. Patients already on treatment were excluded from the study. The determination of ML sub-types was based on WHO criteria. About $3 \mathrm{ml}$ of venous blood were collected in EDTA-containing tubes after obtaining written informed consent from each patient or their parents for those aged under 18 years to participate in this study. Personal and clinical data including age, sex, and past medical history were collected using a questionnaire. In all cases, the blood sample was used for complete blood counts using a five-part automated analyser (Sysmex XP-300 TM, Kobe, Japan).

\section{Morphological and immunohistochemical studies}

From clinically suggestive lymphoma patients, consecutive excisional biopsies were obtained. The specimens related to lymph nodes (104 cases), abdominal tissues (13 cases), spleens (8 cases), soft tissues ( 5 cases), and head-neck tissues ( 4 cases). Using well fixed, processed, and embedded biopsy, multiple sections were selected and then stained with H\&E, and wherever required, special staining was performed for the examination of histological pattern and infiltration. Three expert haematopathologists then reviewed all of the cases. Each expert independently reviewed all of the data available for each case. A consensus diagnosis was reached when two of the experts agreed on the diagnosis. H\&E staining allowed sorting lymphomas between HL and NHL, according to the presence of different cells. Morphological diagnosis of HL cases was based on the effacement of nodal architecture by diffuse small lymphocyte cell, mononuclear, and multinucleated lymphocyte cell, prominent nucleus, a feature of Reed Sternberg cell, a feature of Hodgkin's cell, aggregated stroma with reactive histocytes and fibrosis. The included NHL features were effacement of sections by the mononuclear population of lymphocyte cells, dysplasia, increased $\mathrm{N}: \mathrm{C}$ ratio, suppressing normopoeisis, and mixed cellular infiltration. DLCL presented with a diffused infiltrate of large noncleaved or transformed lymphocytes. Follicular lymphoma was characterised by effacement with mononuclear lymphocyte, and the centre of nodules were composed of pleomorphic lymphocyte with prominent nuclei as well as crowded, back-to-back neoplastic follicles, lack of zonation and tingible body macrophages, numerous cleaved cells, and loss of the mantle zones. BL sections presented with focal and effaced mononuclear cells, prominent nuclei and suppressing normal hemopoiesis. Malt lymphoma sections showed multiple fragments of gastric mucosa infiltrated by a mononuclear population of enterocyte-like lymphocyte destructive gastric gland (lymph epithelial lesion) adjusted showing intestinal metaplasia. T cell lymphoma presented with fragment mesenteric lymph node showing the suggestive feature of hyperplasia, no malignancy was observed in the section but extensive necrosis was found, visible cells showed a sheet of irregular lymphocytes with scattered macrophages.

Immunohistochemistry staining was prepared on specimens embedded with paraffin wax from the main tumours to confirm the morphological diagnosis by following the same techniques described in [11]. A panel of markers was selected based on morphologic diagnosis, including CD3, CD20, CD10, CD15, CD5, and CD30.

\section{Statistical analysis}

Data analysis was performed using Statistical Package for the Social Sciences (SPSS version 20.0) and Microsoft Office Excel 2010 for Windows. Qualitative and quantitative variables were described. The criterion for statistical significance was $\mathrm{P}<0.05$.

\section{Results}

The 134 patients diagnosed with lymphoma were distributed into the traditional categories of non-Hodgkin and Hodgkin lymphoma and are included, along with sub-type and gender in Table 1. Seventeen (12.7\%) cases were diagnosed as HL, whereas $46(87.3 \%)$ were classified as NHL. Regarding HL, four subtypes were identified: mixed cellularity was the most prevalent subtype (41.2\%), followed by nodular sclerosis and lymphocyte-rich (4 case; $23.5 \%$ for each), and lymphocyte-depleted lymphoma $(11.8 \%)$. Of the NHL subtypes, DLBCL was the most prevalent type, representing 46 of the 117 cases (39.3\%). BL was the second most common type, with 40 diagnosed cases $(34.2 \%)$, followed by follicular lymphoma and small lymphocytic with a rate of 9 cases $(7.7 \%)$ for each. Males were predominant in both types of lymphoma with overall 81 (60.4\%) males and $53(39.6 \%)$ females, a male: female ratio of 1.5:1. Among HL patients, 12 out of 17 patients $(70.6 \%)$ were males, and $(29.4 \%)$ females. In NHL patients, males and females were (69 cases; 59\%, 48 cases; $41 \%$, respectively).

Concerning age, as shown in Table 2 , thirty nine $(29.1 \%)$ were $>60$ years of age, and $(70.9 \%)$ were $<60$ years of age. The youngest of these patients was four years old and the oldest 80 years old, with a mean age of 41 years. 
Table 1. Frequency of Lymphoma and Lymphoma Subtypes within Studied Subjects Classified by Gender

\begin{tabular}{lccc}
\hline Lymphoma Sub-types/Gender & Male & Female & Frequency \\
\hline Hodgkin's lymphoma (HL) & 12 & 5 & $17(12.7 \%)$ \\
Nodular sclerosis & 3 & 1 & $4(23.5 \%)$ \\
Mixed cellularity type & 5 & 2 & $7(41.2 \%)$ \\
Lymphocyte rich & 2 & 2 & $4(23.5 \%)$ \\
Lymphocyte depleted & 2 & 0 & $2(11.8 \%)$ \\
Non-Hodgkin's lymphoma (NHL) & 69 & 48 & $117(87.3 \%)$ \\
Diffused large B Cell Lymphoma (DLBCL) & 27 & 19 & $46(39.3 \%)$ \\
Burkett's Lymphoma (BL) & 25 & 15 & $40(34.2 \%)$ \\
Small lymphocytic lymphoma & 5 & 4 & $9(7.7 \%)$ \\
Extranodal marginal (MALT) lymphoma & 3 & 1 & $4(3.4 \%)$ \\
Follicular lymphoma & 4 & 5 & $9(7.7 \%)$ \\
T-cell-rich B cell lymphoma & 1 & 0 & $1(0.85 \%)$ \\
Peripheral T cell lymphoma & 3 & 2 & $5(4.3 \%)$ \\
Anaplastic Large Cell Lymphoma & 0 & 1 & $1(0.85 \%)$ \\
Precursor/lymphoblastic lymphoma & 1 & 1 & $2(1.7 \%)$ \\
Total & 81 & 53 & 134
\end{tabular}

Table 2. Age Groups within Lymphomas Cases

\begin{tabular}{|c|c|c|c|c|c|c|c|}
\hline Type of lymphoma/Age group & & $\leq 15$ years & $16-30$ years & $31-45$ years & $46-60$ years & $>60$ years & Total \\
\hline \multicolumn{8}{|l|}{ Hodgkin's lymphoma } \\
\hline Mean \pm SD & Range & 3 & 3 & 2 & 4 & 5 & 17 \\
\hline $47.14 \pm 22.31$ years & $7-70$ years & & & & & & \\
\hline \multicolumn{8}{|l|}{ Non- Hodgkin's lymphoma } \\
\hline Mean \pm SD & Range & 33 & 10 & 18 & 22 & 34 & 117 \\
\hline $40.22 \pm 24.62$ years & 4- 80 years & & & & & & \\
\hline Total (\%) & & $36(26.90 \%)$ & $13(9.70 \%)$ & $20(14.90 \%)$ & $26(19.40 \%)$ & $39(29.10 \%)$ & $134(100 \%)$ \\
\hline \multicolumn{8}{|c|}{ Overall mean of age $=41.13 \pm 24.242$ years $/$ Significance: $\chi^{2}=0.69, P=0.952$} \\
\hline
\end{tabular}

There was no statistically significant difference within age groups $(\mathrm{P}=0.952)$. As shown in Table 3, $109(93.2 \%)$ of $\mathrm{B}$ cell lymphoma cases were identified compared to $8(6.8 \%)$ cases belonging to $\mathrm{T}$ cell lymphoma. The expression of CD20 was identified in all B cell lymphomas and was not detected in any $\mathrm{T}$ cell lymphomas. CD3 was expressed in all $\mathrm{T}$ cell lymphomas and was also seen in one case of diffuse large B cell lymphoma. All HL cases expressed CD30 and CD15, with no expression of CD3, CD5, and CD10. CD20 was detected in the lymphocyte-rich subtype and one case of mixed cellularity type.

Haematological changes in patients with lymphoma are listed in Table 4. The prevalence of anaemia was evaluated by measuring the haemoglobin concentration. At enrolment, it was observed that all HL patients had anaemia with a mean haemoglobin level of $9.81 \mathrm{~g} / \mathrm{dl}$, ranging from 7.3 to $11.6 \mathrm{~g} / \mathrm{dl}$. Eighty-seven NHL patients $(74.4 \%)$ had anaemia, with an average haemoglobin level of $10.7 \mathrm{~g} / \mathrm{dl}$. Leucocytosis of a variable degree was observed in $56(47.9 \%)$ of NHL cases. The mean platelet count among patients with HL and NHL was 389.17 and $261.88 \times 10^{9}$ cell/L, respectively. Thrombocytosis was observed in seven cases $(41.2 \%)$ of patients with HL. The mean leucocyte count was 18.65 and $17.02 \times 10^{9}$ cell/L in HL and NHL patients, respectively.

\section{Discussion}

This study confirms that diffuse large B cell lymphoma as an NHL subtype, and mixed cellularity in HL subtype are highly prevalent in Sudanese malignant lymphoma patients. The current study was conducted to provide data that may contribute to better health planning and understanding of potential predisposing factors for ML in Sudan, by investigation the relative distribution of various types of ML not previously investigated. In developing countries the prevalence and incidence rates of lymphoma as well as the distribution of lymphoma subtypes may vary (12-14). In the current study, HL and NHL were diagnosed in $12.7 \%$ and $87.3 \%$ of cases, respectively, which is consistent with the results of a survey conducted among ML patients in the United Kingdom, [15] Poland, [16] and also in ML patients in the United States [17] and Chinese ML patients [18]. However, among NHL subtypes in the present study, diffused large B cell lymphoma was the most prevalent subtype, which was identified in $39.3 \%$ of patients. Similar findings were reported in Sudan [19], as well as in India [20]. DLBCL has also 
Table 3. Markers of Expression within Lymphomas Cases

\begin{tabular}{|c|c|c|c|c|c|c|}
\hline Lymphoma Sub-types/Immuophenotype & CD 3 & CD5 & CD10 & CD15 & CD20 & $\mathrm{CD} 30$ \\
\hline \multicolumn{7}{|l|}{ Hodgkin's lymphoma } \\
\hline Nodular sclerosis & - & - & - & + & - & + \\
\hline Mixed cellularity type & - & - & - & + & \pm & + \\
\hline Lymphocyte rich & - & - & - & + & + & + \\
\hline Lymphocyte depleted & - & - & - & + & - & + \\
\hline \multicolumn{7}{|l|}{ Non- Hodgkin's lymphoma } \\
\hline Diffused large B Cell Lymphoma (DLBCL) & $\pm *$ & \pm & \pm & NA & + & NA \\
\hline Burkett’s Lymphoma (BL) & - & - & + & NA & + & NA \\
\hline Small lymphocytic Lymphoma & - & + & - & NA & + & NA \\
\hline Extranodal marginal (MALT) lymphoma & - & - & - & NA & + & NA \\
\hline Follicular lymphoma & - & - & \pm & NA & + & NA \\
\hline T-cell-rich B cell lymphoma & + & + & - & - & + & NA \\
\hline Peripheral T cell Lymphoma & + & + & - & NA & - & NA \\
\hline Anaplastic Large Cell Lymphoma & + & + & - & + & - & + \\
\hline Precursor T lymphoblastic Lymphoma & + & + & + & - & - & NA \\
\hline
\end{tabular}

been documented to be the most frequent NHL subtype in most studies worldwide, and geographic variations in NHL subtypes are well documented. In Pakistan $66.1 \%$ of NHL cases were reported to be of DLBCL subtype [21]. In some African countries the distribution of NHL subtypes varies according to age group, with DLBCL accounting for $55 \%$ of all NHL cases among adults, [22] and BL comprising nearly $50 \%$ of childhood cases of NHL in Africa [23]. Regarding HL, mixed cellularity, was the more predominated type in the present study. Results were consistent with those found among Ethiopian ML patients [24]. In our study, the male gender group was more predominant in both types of lymphoma, with overall frequencies of $60.4 \%$ in males, and $39.6 \%$ in females. Among HL patients, 12 out of 17 patients were males. In NHL patients, males represented $59 \%$ of cases. These results are consistent with worldwide observations, which show that both ML and other haematological malignancies often occur more frequently in males than in females [17]. Concerning the characteristic patterns of lymphoma cells, B-cell lineage dominated in our current data $(94 \%)$, compared to a low relative proportion of $\mathrm{T}$ cell lymphomas $(6 \%)$. These findings are in agreement with previous studies [25]. However, the distribution of $\mathrm{T}$ cell lymphoma varies worldwide, ranging from a low frequency of about 4\% such as in Korea [26], to more a frequent rate, such as $23 \%$ in Turkey [27]. In the present study, in ML cases expression of CD3 and CD20 were the most specific surface antigens for lymphocytes. CD20 was expressed in all B cell lymphomas and was negative in all T cell lymphomas while CD3 was expressed in all T cell lymphomas, and in one case of large B cell lymphoma. These results are consistent with previous studies in ML cases. Regarding the finding of one large B cell

Table 4. Variables of Peripheral Blood Parameters within Lymphomas cases

\begin{tabular}{lccc}
\hline Haematological variables/ Type of Lymphoma & Hodgkin's lymphoma & Non- Hodgkin's lymphoma & P-value \\
\hline Haemoglobin $($ Mean \pm SD) g/dl & $9.81 \pm 1.72$ & $10.7 \pm 2.17$ & 0.312 \\
Range of haemoglobin g/dl & $7.30-11.60$ & $6.00-15.20$ & -- \\
Normal haemoglobin level N (\%) & $0(0.00 \%)$ & $30(25.6 \%)$ & 0.084 \\
Low haemoglobin level N (\%) & $17(100 \%)$ & $87(74.4 \%)$ & 0.082 \\
Leucocyte count (Mean \pm SD) cell/L & $18.65 \pm 34.23$ & $17.02 \pm 41.81$ & 0.098 \\
Range of leucocyte count, cell/L & $2.30-96.00$ & $1.00-272.00$ & -- \\
Normal leucocyte count N (\%) & $12(70.6 \%)$ & $49(41.9 \%)$ & 0.332 \\
Leucocytosis N (\%) & $3(17.6 \%)$ & $56(47.9 \%)$ & 0.028 \\
Leucocytopenia N (\%) & $2(11.8 \%)$ & $12(10.3 \%)$ & 0.849 \\
Platelets count, cell/L (Mean \pm SD) & $389.17 \pm 239.46$ & $261.88 \pm 161.45$ & 0.097 \\
Range of platelets count, cell/L & $41.00-762.00$ & $15.00-636.00$ & -- \\
Normal platelets count N (\%) & $5(29.4 \%)$ & $71(60.7 \%)$ & 0.021 \\
Thrombocytosis N (\%) & $7(41.2 \%)$ & $18(15.4 \%)$ & 0.015 \\
Thrombocytopaenia N (\%) & $5(29.4 \%)$ & $28(23.9 \%)$ & 0.624 \\
\hline
\end{tabular}


lymphoma case that gave a positive reaction for $\mathrm{CD} 3$, the same result has been reported in rare instances of mature B-cell neoplasms in some studies [28-30]. The explanation behind this odd finding remains unclear. However, several mechanisms have been suggested to clarify the aberrant expression of T-cell antigens by neoplastic B cells [31, $32]$. Concerning the age of our study subjects, $29.1 \%$ were $>60$ years of age, and $70.9 \%$ were $<60$ years of age. The youngest of these patients was four years old and the oldest 80 years old, with a mean age of 41 years. These results were consistent with Caminha et al. study [33]. Evaluations of peripheral blood parameters are required as part of pre-treatment check-up in cases of lymphoma, parameters which are also reflective of prognostic inferences, especially if an abnormality is found [34]. In the current study, anaemia was the most frequent feature, found in all HL patients and the majority of NHL patients $(74.4 \%)$. Leucocytosis was observed in $47.9 \%$ of NHL cases. Thrombocytosis was detected in $41.2 \%$ and $15.4 \%$ of patients with HL and NHL, respectively. Further, the frequency of leucopenia was observed in $11.8 \%$, and $10.3 \%$ of patients with HL and NHL, respectively. These haematological variables did not show any statistically significant differences within studied lymphoma patients. These abnormalities, also observed in previous studies, may be initiated by the influence of cytokines released by malignant cells, and also as a consequence of bone marrow replacement by ML cells at the late stage of the disease [35-36]. ML in Sudanese patients was more frequent in males than in females; its incidence increases with age. $\mathrm{B}$ cell lymphoma is more common than T cell lymphoma. DLBCL was the most frequent NHL subtype.

\section{Acknowledgments}

I thank the staff of the Radioisotope Centre of Khartoum (RICK), especially the haematopathologists and clinicians, for their great help in sample collection and diagnosis. I would also like to thank all the participants who took part in this study.

\section{Funding}

This research did not receive any specific grant from funding agencies in the public, commercial, or not-forprofit sectors.

\section{Conflict of Interest}

None

\section{References}

1. Campo E, Swerdlow SH, Harris NL, Pileri S, Stein H, Jaffe ES. The 2008 WHO classification of lymphoid neoplasms and beyond: evolving concepts and practical applications. Blood. 201105 12;117(19):5019-5032. https://doi.org/10.1182/ blood-2011-01-293050

2. Küppers R. The biology of Hodgkin's lymphoma. Nature Reviews Cancer. 2008 Dec 11;9(1):15-27. https://doi. org/10.1038/nrc2542

3. Swerdlow SH, Campo E, Pileri SA, Harris NL, Stein H, Siebert R, Advani R, Ghielmini M, Salles GA, Zelenetz
AD, Jaffe ES. The 2016 revision of the World Health Organization classification of lymphoid neoplasms. Blood. 201605 19;127(20):2375-2390. https://doi.org/10.1182/ blood-2016-01-643569

4. Bray F, Ferlay J, Soerjomataram I, Siegel RL, Torre LA, Jemal A. Global cancer statistics 2018: GLOBOCAN estimates of incidence and mortality worldwide for 36 cancers in 185 countries. CA: A Cancer Journal for Clinicians. 2018 09 12;68(6):394-424. https://doi.org/10.3322/caac.21492

5. Saeed M, Cao J, Fadul B, et al. A Five-year Survey of Cancer Prevalence in Sudan. Anticancer Res. 2016;36:279-86.

6. Schmid C, Isaacson PG. Bone marrow trephine biopsy in lymphoproliferative disease.. Journal of Clinical Pathology. 199209 01;45(9):745-750. https://doi.org/10.1136/ jcp.45.9.745

7. Venizelos ID, I, Tatsiou ZA, Z, Mandala E E. Primary cutaneous T-cell-rich B-cell lymphoma: a case report and literature review. Acta Dermatovenerol Alp Panonica Adriat. 2008; 17:177-81.

8. Rao I. Role of immunohistochemistry in lymphoma. Indian Journal of Medical and Paediatric Oncology. 2010;31(4):145. https://doi.org/10.4103/0971-5851.76201

9. Xiao W, Wang Z, Wang L. CD20-positive T-cell Lymphoma with Indolent Clinical Behaviour. Journal of International Medical Research. 2010 06;38(3):1170-1174. https://doi. org/10.1177/147323001003800347

10. Armitage JO. Early-Stage Hodgkin's Lymphoma. New England Journal of Medicine. 201008 12;363(7):653-662. https://doi.org/10.1056/nejmra1003733

11. Roudi R, Korourian A, Shariftabrizi A, Madjd Z. Differential Expression of Cancer Stem Cell Markers ALDH1 and CD133 in Various Lung Cancer Subtypes. Cancer Investigation. 201506 05;33(7):294-302. https://doi.org/10.3109/07357 907.2015 .1034869

12. Mohd Noor A, Sarker D, Vizor S, McLennan B, Hunter S, Suder A, Moller H, Spicer JF, Papa S. Effect of Patient Socioeconomic Status on Access to Early-Phase Cancer Trials. Journal of Clinical Oncology. 201301 10;31(2):224230. https://doi.org/10.1200/jco.2012.45.0999

13. Perry AM, Diebold J, Nathwani BN, MacLennan KA, Müller-Hermelink HK, Bast M, Boilesen E, Armitage JO, Weisenburger DD. Relative frequency of non-Hodgkin lymphoma subtypes in selected centres in North Africa, the middle east and India: a review of 971 cases. British Journal of Haematology. 2015 Dec 18;172(5):699-708. https://doi. org/10.1111/bjh. 13876

14. Perry AM, Perner Y, Diebold J, Nathwani BN, MacLennan KA, Müller-Hermelink HK, Bast M, Boilesen E, Armitage JO, Weisenburger DD. Non-Hodgkin lymphoma in Southern Africa: review of 487 cases from The International NonHodgkin Lymphoma Classification Project. British Journal of Haematology. 2015 Dec 21;172(5):716-723. https://doi. org/10.1111/bjh.13885

15. Smith A, Crouch S, Lax S, Li J, Painter D, Howell D, Patmore R, Jack A, Roman E. Lymphoma incidence, survival and prevalence 2004-2014: sub-type analyses from the UK's Haematological Malignancy Research Network. British Journal of Cancer. 201503 24;112(9):1575-1584. https:// doi.org/10.1038/bjc.2015.94

16. Szumera-Ciećkiewicz A, Gałązka K, Szpor J, et al. Distribution of lymphomas in Poland according to World Health Organization classification: analysis of 11718 cases from National Histopathological Lymphoma Register project - the Polish Lymphoma Research Group study. Int J Clin Exp Pathol.7:3280-6.

17. Morton LM, Wang SS, Devesa SS, Hartge P, Weisenburger 
DD, Linet MS. Lymphoma incidence patterns by WHO subtype in the United States, 1992-2001. Blood. $20060101 ; 107(1): 265-276$. https://doi.org/10.1182/ blood-2005-06-2508

18. Sun J, Yang Q, Lu Z, He M, Gao L, Zhu M, Sun L, Wei L, Li M, Liu C, Zheng J, Liu W, Li G, Chen J. Distribution of Lymphoid Neoplasms in China. American Journal of Clinical Pathology. 2012 09;138(3):429-434. https://doi.org/10.1309/ ajcp7yltqpusdq5c

19. Ismail A, Osman I, Husain NE. LMP1 Immunohistochemistry in Non-Hodgkin's Lymphoma of Sudanese Cases. Open Journal of Pathology. 2016;06(02):79-87. https://doi. org/10.4236/ojpathology.2016.62010

20. Nair R, Arora N, Mallath MK. Epidemiology of NonHodgkin's Lymphoma in India. Oncology. 2016;91(1):18-25. https://doi.org/10.1159/000447577

21. Mushtaq S, Akhtar N, Jamal S, et al. Malignant lymphomas in Pakistan according to the WHO classification of lymphoid neoplasms. Asian Pac J Cancer Prev. 2008;9:229-32.

22. Naresh KN, Raphael M, Ayers L, Hurwitz N, Calbi V, Rogena E, Sayed S, Sherman O, Ibrahim HA, Lazzi S, Mourmouras V, Rince P, Githanga J, Byakika B, Moshi E, Durosinmi M, Olasode BJ, Oluwasola OA, Akang EE, Akenòva Y, Adde M, Magrath I, Leoncini L. Lymphomas in sub-Saharan Africa - what can we learn and how can we help in improving diagnosis, managing patients and fostering translational research?. British Journal of Haematology. 201106 28;154(6):696-703. https://doi.org/10.1111/j.13652141.2011.08772.x

23. Hämmerl L, Colombet M, Rochford R, Ogwang DM, Parkin DM. The burden of Burkitt lymphoma in Africa. Infectious Agents and Cancer. 201908 01;14(1). https://doi. org/10.1186/s13027-019-0236-7

24. Getachew A. Malignant lymphoma in western Ethiopia. East Afr Med J.78:402-4.

25. Hamid KH, Yousif BM, Abdel MM, Elduma AH. Immunophenotyping of Non-Hodgkin's lymphomas in Sudan. Pan African Medical Journal. 2014;18. https://doi. org/10.11604/pamj.2014.18.82.3732

26. Yoon SO, Suh C, Lee DH, Chi H, Park CJ, Jang S, Shin H, Park B, Huh J. Distribution of lymphoid neoplasms in the Republic of Korea: Analysis of 5318 cases according to the World Health Organization classification. American Journal of Hematology. 201008 30;85(10):760-764. https://doi. org/10.1002/ajh.21824

27. Sağlam A, Esin E, Hayran M, Boyraz B, Üner A. Distribution of lymphomas in Turkey: data of 4239 cases from a single institution using the WHO classification. Turk J Med Sci. 2018;48:1013-23. https://doi.org/10.3906/sag-1804-107

28. Wu B, Vallangeon B, Galeotti J, Sebastian S, Rehder C, Wang E. Epstein-Barr virus-negative diffuse large $\mathrm{B}$ cell lymphoma with aberrant expression of CD3 and other T cell-associated antigens: report of three cases with a review of the literature. Annals of Hematology. 201607 19;95(10):1671-1683. https://doi.org/10.1007/s00277-016-2749-0

29. Wang J, Chen C, Lau S, Raghavan RI, Rowsell EH, Said J, Weiss LM, Huang Q. CD3-positive Large B-cell Lymphoma. The American Journal of Surgical Pathology. 2009 04;33(4):505-512. https://doi.org/10.1097/ pas.0b013e 318185d231

30. Oliveira JL, Grogg KL, Macon WR, Dogan A, Feldman AL. Clinicopathologic Features of B-Cell Lineage Neoplasms With Aberrant Expression of CD3. The American Journal of Surgical Pathology. 2012 09;36(9):1364-1370. https:// doi.org/10.1097/pas.0b013e31825e63a9

31. Lee M, Cha HJ, Yoon DH, Suh C, Huh J. EBV-positive diffuse large B-cell lymphoma of the elderly with aberrant expression of CD3 and TIA-1. Blood Research. 2013;48(2):156. https://doi.org/10.5045/br.2013.48.2.156

32. Yang L, Ingersoll K, Zhao Y, Luedke C, Sebastian S, Wang E. CD3-positive diffuse large B-cell lymphoma relapses as CD3-negative large B-cell lymphoma: Loss of aberrant antigen expression in B-cell lymphoma after chemotherapy. Pathology - Research and Practice. 2018 Oct;214(10):17381744. https://doi.org/10.1016/j.prp.2018.07.003

33. Caminha B, Neves Rodrigues Vieira G, Bragante Fernandes Pimenta M, et al. Epidemiological Analysis of Lymphoma Subtypes in a Reference Center in João Pessoa, Paraiba, Brazil. Int J Phys Med Rehabil. 2018;6:473.

34. Zhang Q, Foucar K. Bone Marrow Involvement by Hodgkin and Non-Hodgkin Lymphomas. Hematology/Oncology Clinics of North America. 2009 08;23(4):873-902. https:// doi.org/10.1016/j.hoc.2009.04.014

35. Durosinmi M, Mabayoje V, Akinola N. A review of histology of bone marrow trephine in malignant lymphomas. Nigerian journal of medicine : journal of the National Association of Resident Doctors of Nigeria. 2003;12(4):198-201.

36. Mustafa A, Fatima Bhopalwala A. Incidence of Hodgkin's \& Non Hodgkin's Lymphomas and Comparison of Their Hematological Parameters. JMSCR. 2018;6:218-21.

\section{(1) 8}

This work is licensed under a Creative Commons AttributionNon Commercial 4.0 International License. 